\title{
Claribel Alegría: mujer que se compromete. Cenizas de Izalco: obra que delata
}

\author{
Ana Cecilia Vilá de Lara \\ Especialista en estudios culturales, \\ literatura latinoamericana y enseñanza \\ y aprendizaje del español \\ Doctora en Lenguas español/ italiano \\ cecilia.lara@uncp.edu
}

\section{Resumen}

En este artículo se exploran los acontecimientos sociales y los momentos de violencia en El Salvador, particularmente en el año clave de 1932, en la novela de Cenizas de Izalco de Claribel Alegría. A través de un acercamiento de género, se explora cómo Alegría usa la representación tradicional de la mujer, como la mejor manera de poner en evidencia las injusticias sociales ante el lector.

Palabras clave: Claribel Alegría, compromiso, social, Cenizas de Izalco, denuncia, Maximiliano Hernández Martínez, Masacre del 32, violencia, política, opresión, mujer, femenino/a, género, salvadoreña, El Salvador.

\begin{abstract}
In this paper I explore social events and violence in El Salvador, particularly during the key year of 1932 and in the work Ashes of Izalco by Claribel Alegría. Through a gender approach, I explore how Alegría uses traditional representations of women to demonstrate evidence of social injustice to readers.

Keywords: Claribel Alegría, social commitment, Ashes of Izalco, denunciation, Maximiliano Hernández Martínez, Massacre of 1932, violence, politics, oppression, woman, female, gender, Salvadoran, El Salvador.
\end{abstract}

Antes de ser conquistado por los españoles, El Salvador era llamado Cuzcatlán ${ }^{1}$, que significa "país de preseas" o "ciudad alhaja". ${ }^{2}$ Eso es lo que realmente es El Salvador, una tierra de cosas preciosas en cuanto a su riqueza por su exuberante

1 Cuscatlán, en la actualidad.

2 De acuerdo con Pedro Geoffroy Rivas, en su Toponimia náhuat de Cuscatlán. 
vegetación, cerros y volcanes, que son bellos y fértiles. Ha sido por medio de los diversos cultivos que se han producido en esas tierras que se ha permitido a El Salvador tener una trayectoria en el desarrollo agrícola y comercial desde el tiempo de la Colonia.

A pesar de esta riqueza, El Salvador ha sido cuna de una lucha continua entre sus habitantes por la tenencia de la tierra. Este enfrentamiento y la lucha generada han movido a muchos escritores a comprometerse con su patria y a contar su historia. El objetivo de este estudio es analizar una obra literaria de una escritora que, en su género, proyecta y divulga el dolor, la injusticia y la deshumanización de un pueblo que sufre.

En este texto se presenta una novela de Claribel Alegría que, a través de su literatura, se percibe su misión hacia El Salvador y que en su propio estilo literario narra una historia de dolor y de sufrimiento social que ha teñido de sangre a la tierra cuzcatleca. Es precisamente esa visión de compromiso con su pueblo lo que ha motivado a estudiarla. Claribel Alegría plasma momentos fríos vividos en un país totalmente ardiente; en donde existe una extrema pobreza y en el que las luchas entre las clases han marcado su trayectoria. Si se utiliza el adjetivo frío, es para dejar plasmada la idea de lo deshumanizante que pueden llegar a ser esas luchas sociales, cargadas de violencia y de sangre. Son enfrentamientos bélicos que de un modo u otro afectan a toda la nación.

Claribel Alegría nos ofrece una novela impregnada de hechos reales. Dentro de su obra literaria, su novela le sirve de instrumento para canalizar los desequilibrios sociales y la violencia política. El interés hacia esta escritora se debe, pues, a que ella presenta un compromiso social en su obra. Se ha elegido la novela Cenizas de Izalco para demostrar el profundo compromiso social de la autora. Pero además, interesa acercarse desde una perspectiva de género. Claribel Alegría utiliza la representación tradicional de la mujer como un ser más apto para la expresión de sentimientos y pasiones, para lograr, emotivamente, hacer una profunda denuncia social. La historia que ella cuenta pudo haber sido contada por cualquiera. Sin embargo, el efecto que ella ha logrado, al hacer de ello una obra literaria, ha sido el de alterar los sentimientos para conmover al lector y por este medio reconocer la injusticia. Ella utiliza esa representación tradicional para denunciar "emocionalmente" el dolor ocasionado por la violencia y el terror que los conflictos sociales han producido a la población salvadoreña desde siempre. Es una mujer que transgrede la frontera literaria para hacer un llamado a la memoria colectiva y no dejar que los sucesos que marcaron El Salvador sean olvidados.

Elegir a Claribel Alegría, que nace en 1924, no es arbitrario. Ella pertenece a una generación de extrema violencia política y utiliza su obra para hacer una rotunda denuncia social de la violencia que históricamente ha tenido que afrontar la población salvadoreña y que forma parte de la etapa histórica que le tocó vivir. La 
historia de El Salvador no se conforma de hechos aislados, sino por el contrario, desde la expropiación de las tierras indígenas por los conquistadores, pasando por los conflictos entre moderados y conservadores tras la Independencia, y por una clara corrupción de la clase política salvadoreña, la violencia política y social ha sido una realidad. Cenizas de Izalco es principalmente el año de 1932. El marco histórico de El Salvador durante esa época es sumamente conflictivo en todo aspecto. Fue un tiempo de revoluciones, luchas de clases sociales, organizaciones sociopolíticas, y sobre todo violencia. Entre todos estos conflictos se dio uno que atañe directamente a este ensayo. Fue el de la lucha de la mujer por su dignificación como ciudadana dentro de una sociedad igualitaria. En cuanto al papel de la mujer salvadoreña, se puede decir que, en lo general, seguía uno similar al prototipo de la mujer española del siglo XIX, más específicamente con el modelo que ofrece Pilar Sinués en sus publicaciones de El Angel del Hogar (Guardia, 2007, p.20). Prepararse y cultivarse eran partes importantes, especialmente en la mujer de sociedad, pero con el único objetivo de atender los asuntos del hogar. Sin embargo, en El Salvador también existieron mujeres emprendedoras que pensaron que el papel de la mujer podía ir más allá del entonces establecido. Eran mujeres transgresoras, ya que condujeron a cambios políticos importantes. Una de estas, y quizás la más importante como precursora de cambios en el bienestar de la mujer, fue Prudencia Ayala.

Prudencia Ayala nació en 1885 y murió en 1936; ha sido un personaje representativo de la mujer salvadoreña en busca del cambio. Ella no solo aportó sus enfoques a través de la literatura, sino que luchó activamente por los cambios sociales y políticos de su país.

Prudencia Ayala fue la primera mujer salvadoreña en exigir el reconocimiento de sus derechos de ciudadana y en utilizar sus escritos literarios para reivindicar los derechos de las mujeres (Duarte, 1973, p. 16).

En el año de 1930, Prudencia Ayala lanzó su candidatura para presidenta de la República. En los preparativos de su campaña monta cajones de madera para poner su tarima como tribuna y desde allí exponer, a fuerza de garganta, los problemas de las elecciones y la falta de igualdad de género. La siguiente frase era una de sus quejas en contra del sistema legal: “¿Cómo podría ser yo Jefe nacional, cuando el sexo femenino no tiene establecido en la Constitución el derecho al sufragio, que en justicia merece ser parte integrante de toda sociedad humana?" (Murcia, Clic.org).

El siguiente párrafo es parte de un discurso dado en homenaje a Prudencia Ayala.

San Salvador, 11 de julio de 2006. La Licda. María Isabel Villegas dijo lo siguiente:

Prudencia Ayala fue una mujer que se adelantó a su época, una visionaria que desafió a principios del siglo pasado las prohibiciones de una cultura 
patriarcal autoritaria que la calificó de loca, porque denunciaba la pobreza, la injusticia y la hipocresía (Iglesia, Ecuménico).

Todo este movimiento hacia la aceptación de la ciudadanía de la mujer es parte del marco histórico de El Salvador durante el tiempo narrativo de Cenizas de Izalco. Claribel Alegría, al igual que Prudencia Ayala, es una mujer que como escritora promulga la libertad femenina como derecho de ella misma para tomar sus propias decisiones. Por medio de las figuras literarias y por la narrativa del discurso, se deja entrever el aspecto de cómo la mujer había sido vista tradicionalmente y la lucha interna de ella por liberarse de esas normas sociales establecidas.

Hay varios tipos de discursos presentes en la obra. Entre ellos están el de las injusticias sociales y el de la guerra, que serán puntualizados en esta investigación, pero también está fuertemente tocado el discurso que norma el comportamiento de las mujeres solteras; el discurso de la mujer como ama de la casa, que es parte del discurso normativo. Dentro de este hay otro que se debe tratar, que es el de la mujer sin derechos como ciudadana, que aun cuando Claribel Alegría no le da mucha importancia dentro de la novela, lo toca lo suficiente como para advertir el mensaje. Cenizas de Izalco fue publicada en 1966, pero la historia del libro se remonta a los años 30, por lo que es necesario recordar que el sufragio femenino no fue otorgado sino hasta 1938, dos años después de la muerte de Prudencia Ayala.

En este texto se presenta una serie de datos sobre los sucesos más relevantes de la historia de El Salvador, la cual fue una realidad que influyó en gran manera en la vida de Alegría. Primero, se estudia la dictadura del general Maximiliano Hernández Martínez, presidente de El Salvador (1931-1944), quien fue la figura política que prevaleció durante la niñez y juventud de Claribel. Luego se presentará un análisis de la obra elegida para demostrar el profundo compromiso social de esta escritora con un aspecto de la realidad salvadoreña.

\section{El Salvador 1890-1932}

A finales del siglo XIX e inicios del XX, El Salvador era considerado como una República de alta producción cafetalera. El cultivo de este grano permitió, paulatinamente, la concentración de grandes capitales en ciertos grupos privilegiados, formando así los latifundios. Estas familias o grupos privilegiados ejercían una gran influencia en el poder político del país debido a su tremendo poder económico. Una de las mayores atribuciones que tuvieron fue en la elección de una serie de presidentes civiles pertenecientes a familias del mismo gremio económico y social. Como explica Peñate, una de las familias más importantes y que ocupaban los cargos más altos en el partido político democrático era la dinastía Meléndez-Quiñónez (1913-1927) (Peñate 2002, pp. 79-80). El presidente anterior a Alfonso Quiñónez Molina fue Carlos 
Meléndez (1913-1914; 1915-1918). Luego pasó a la presidencia su hermano Jorge Meléndez (1918-1923); que al mismo tiempo eran cuñados de Alfonso Quiñónez Molina, quien ejerció el cargo de vicepresidente y que para el año de 1923 fue elegido presidente de la República y, por tanto, continuó un gobierno que favorecía los intereses de la clase dirigente del país.

Esta corrupción a escala nacional causó una desintegración económica y de resentimiento social en las grandes masas populares. Entre las protestas sociales que ocurrieron, la manifestación de mujeres tiene vital importancia para este trabajo, ya que documenta a las mujeres como parte activa de la sociedad. Así mismo, en El Salvador, durante esa misma época, surgen los primeros movimientos a favor de la superación de las mujeres, liderados por Alice Lardé de Venturino, quien fue la primera mujer de América que se incorpora como miembro de la Academia de Ciencias y Bellas Letras y Nobles Artes de Córdoba, España. Según Duarte (1973), Alice Lardé lo hizo como seguidora de la lucha de Prudencia Ayala, primera mujer en exigir el reconocimiento de los derechos de ciudadana y en utilizar sus escritos literarios para reivindicar los derechos de las mujeres (p.16).

Son las mujeres las que se organizan para protestar pacíficamente sobre el fraude electoral en contra de Tomás Molina, candidato que se presentaba para presidente pero fue derrocado por Alonso Quiñónez. La presidencia de Quiñónez duró cuatro años. Durante este tiempo, campesinos y obreros comienzan a organizarse en asociaciones, confederaciones y sindicatos para luchar por sus derechos. Vale la pena mencionar la situación internacional que simultáneamente se está dando. En el libro de El Salvador. Historia General, Óscar Martínez Peñate señala que

La Primera Guerra Mundial (1914-1918) y el triunfo de la Revolución rusa (1917); en el ámbito regional la Revolución mexicana (1910-1917) y el antiimperialismo del pueblo nicaragüense liderado por Augusto César Sandino, gravitaron de alguna manera en la vida política, económica y social salvadoreña de este período (80).

En 1927, Romero Bosque sucedió a la presidencia de Alonso Quiñónez y gobernó hasta 1931. El país también se vio afectado por la depresión económica mundial de 1929, por lo que su gobierno resultó dañado cuando el café sufrió una gran caída de precio y muchos productores dejaron que su cosecha se pudriera en las plantaciones en lugar de contratar a los campesinos para cortar el grano. En 1930 hubo una petición exigiendo una ley que garantizara los contratos laborales: "Garantizar los contratos laborales en las fincas y establecer un salario mínimo para los trabajadores agrícolas". Los problemas se multiplicaron, y para cuando Bosques dejó la presidencia alrededor de mil doscientas personas habían sido encarceladas por actividades izquierdistas o agitación obrera (Parkman 2003, p. 50). 
El ingeniero Arturo Araujo subió a la presidencia en marzo de 1931, pero en diciembre del mismo año el general Maximiliano Hernández Martínez dio un golpe de Estado, quedándose como presidente dictador por los sucesivos catorce años. En estos años de dictadura se vivió la masacre de 1932, masacre que marcó una brecha en la historia de El Salvador. El Partido Comunista Salvadoreño se alzó en armas. Las tropas del gobierno descubrieron el complot. Se produjo una matanza de miles de campesinos, en su mayoría del occidente del país, y de líderes populares, entre ellos Feliciano Ama y Agustín Farabundo Martí, este último era el líder principal de las actividades izquierdistas y luego mártir de la guerrilla salvadoreña.

\section{Claribel Alegría y Cenizas de Izalco}

A pesar de que Claribel Alegría es coautora con su esposo Darwin Flakoll del libro Cenizas de Izalco, en este ensayo se otorga igual responsabilidad a cada una de las partes escritas por los autores. De esta manera, y de acuerdo con la posición de Seidy Araya, es de suponer que fue el enriquecimiento de sus partes lo que le dio la globalidad a la novela.

Claribel Alegría nació como Clara Isabel Alegría Vides en Estelí, Nicaragua. Desde los nueve meses de edad se trasladó con su familia a la ciudad de Santa Ana, El Salvador. Su padre era médico nicaragüense y su madre salvadoreña. Su familia se vio forzada al exilio, por lo que se instalaron en esa ciudad. Allí estudió en el colegio "José Ingenieros", que había sido fundado por su tío Ricardo Vides. Para el año de 1943, Claribel se muda a los Estados Unidos para asistir a la George Washington University, donde recibió una licenciatura en Artes y Filosofía. En el año de 1947 se casa con Darwin J. Flakoll, periodista y diplomático estadounidense, con quien tuvo tres hijos. Claribel y su familia tuvieron la oportunidad de viajar y vivir en diversos países y ciudades importantes, entre ellos Chile, Buenos Aires, Montevideo, París y Nicaragua. Mantuvo amistad con figuras literarias importantes, tales como Mario Vargas Llosa, Juan Rulfo, Julio Cortázar, Carlos Fuentes y Mario Benedetti. En el año de 1950 se convirtió en socia honoraria del Ateneo Americano. Trabajaron numerosos escritos literarios en conjunto con su esposo, a quien llamaba Bud, y con quien a veces firmaban como Claribud. Su esposo muere en el año de 1979.

Sus publicaciones son ricas en libros de poesía, cuentos y novelas. Su primera obra fue Anillos del silencio, publicada en el año de 1948. En el 2006 obtiene el Premio Internacional Neustadt de Literatura.

Acerca de la narrativa de Claribel Alegría, dice Araya (2003): "Se afirma la referencialidad de los textos en el sentido de que recuperan grandes hechos históricos y se inspiran en costumbres centroamericanas" (p.19). Cenizas de Izalco no se aparta de las afirmaciones de Araya, es una novela que captura 
hechos históricos de El Salvador. Según Gil Casado, para que una novela sea considerada novela social debe tratar sobre el estado de la sociedad, sus injusticias o desigualdades, así también se debe referir a un sector o a la totalidad de la sociedad. Asimismo, debe de existir testimonio que sirva de base a una denuncia o crítica y tiende hacia el realismo colectivo (p. 66). Siguiendo la clasificación definitoria de Gil Casado, Cenizas de Izalco es una novela social, ya que trata sobre el estado específico en que se encontraba la sociedad de El Salvador, así como las injusticias llevadas a cabo en un sector específico de la sociedad. Es una novela que tiene testimonio de denuncias sociales y encierra un realismo colectivo, pues presenta los problemas específicos que el sector campesino padeció.

El marco histórico presente en la novela es el de los años 60 del siglo XX, aunque hace referencias a la década de los años cincuenta para indicar la inmovilidad social del país. Pero al mismo tiempo nos ubica en los años de 1930 a 1932 . El lector vive intensamente la masacre o genocidio del año de 1932, recuperando de esta manera la historia de años de violencia real vivida en El Salvador y sufrida más en las ciudades al occidente del país. Cenizas de Izalco se desarrolla en la ciudad de Santa Ana.

El argumento de la obra se centra en el personaje de Carmen, que vive en los Estados Unidos, específicamente en Washington, y va al entierro de su madre, Isabel, señora perteneciente a la alta sociedad de Santa Ana. El padre de Carmen, el Dr. Alfonso Rojas, su hermano Alfredo y su tío Eduardo, hermano de Isabel, forman la familia principal de Carmen. Una familia que representa un estatus de clase media alta en la sociedad salvadoreña. Frank Wolff es uno de los personajes principales de la novela Cenizas de Izalco. Frank es un forastero norteamericano que llegó a Santa Ana, escapando de una vida vacía a la que el alcoholismo lo había llevado. Frank se hospeda en la casa de otro norteamericano, Virgil, amigo de su juventud y ahora misionero evangelista. Frank era un escritor, pero su vicio lo había alejado de su oficio. Es a través del diario de Frank, que le fue dado a Carmen por voluntad de Isabel, que a Carmen se le revela el otro rostro de su madre. "La dejamos sola entre sus muertos. Frank se llevó con él un rostro distinto de mamá, uno que nunca adiviné” (Alegría, 1987, p. 175). Para Carmen, Isabel era la figura mitificada de lo que era una madre, esposa y ama de casa. Nunca se pudo haber imaginado que su madre no hubiera sido feliz y que tuviera sentimientos amorosos hacia otro hombre que no fuera su padre.

Es el diario de Frank el recurso literario que la escritora Claribel Alegría utiliza para presentar el pasado relativo de la novela, donde las alusiones se remontan a treinta años atrás del momento en que transcurre la obra.

Como señala Araya, en un estudio de la obra de Alegría (1987), "los efectos semánticos se logran mediante la yuxtaposición de fragmentos paralelos del pasado (1931-1932) y el presente (años cincuenta y sesenta)" (p. 21). En 
esa interposición de datos se nos van presentando momentos íntimos de los personajes, principalmente entre Isabel, la madre de Carmen y el mismo Frank, así como sus relaciones familiares, situaciones costumbristas de la sociedad, hechos crueles e históricos, tan reales como la erupción del volcán de Izalco en 1932 y el levantamiento armado del mismo año, que marcaron al pueblo salvadoreño.

Las normas sociales esperaban que la mujer se casara. La sociedad había propuesto los modos de comportamiento, desde niñas; la mujer había sido criada para eso, para ser ama de casa. Era lógico que al salirse de ese esquema los grados de frustración fueran expresados de diversas maneras y por tanto sufrieran de inadaptación dentro de la sociedad.

Hace años, cuando regresé por primera vez la volví a ver. Luego cuando regrese con Paúl y mis hijos, y ahora, hace dos dias. Cada vez más vieja, más marchita. Una araña que nunca atrapó nada; allí encogida en el centro de su red (...). Toda una vida de amargura estólida y pública resignación (...). La inmovilidad de la señorita Soto es un reto a la ciudad, una burla al movimiento (...) que piensan que algo pasa en Santa Ana (Alegría, 1987, p.17).

Está clara la analogía de la ciudad y la mujer, donde el tiempo lineal transcurrido ha sido representado por la pasividad de la mujer, por la que han pasado los años y sigue igual, a la espera de un cambio, en su condición social, pero de una forma totalmente pasiva. La representación de estar estancada en el tiempo la hace nuevamente con la metáfora de la telaraña. Sobre esto nos dice Cirlot: "La araña en su tela es considerada en la India como Maya, la eterna tejedora en el velo de las ilusiones (...). El simbolismo de la araña penetra profundamente en la vida humana para significar aquel sacrificio continuo" (Cirlot, 1997, p. 85).

Carmen vuelve a hacer alusión a la norma sobre la mujer soltera. Son todos estos pasajes, en la voz de Carmen (voz femenina), que expresan ese discurso donde presentan la visión de la mujer soltera.

En mi Santa Ana no hay lugar para las tías solteronas. Puede ser que esté cambiando, pero hace veinte años el único futuro para las señoritas de "sociedad" era casarse con cualquiera, siempre y cuando ese cualquiera perteneciera a una familia conocida. Lo único que se les permitía hacer a las tías vírgenes era dulces para los sobrinos, tapetes de crochet y bizcochos (Alegría 1987, p. 25).

Pareciera que el modelo de la mujer de Pilar Sinués fuera una norma de comportamiento generalizada y popularizada en El Salvador a principios del siglo XX. Las jóvenes solteras o adultas solteras no tenían mucha opción. Su papel conductual ya estaba predeterminado por la sociedad, en este caso, de Santa Ana, lo cual es lo mismo para el resto del país. 
De este modo se puede observar ese discurso de la mujer como ama de casa y sin derechos de ciudadana. Carmen analiza la vida de su madre; y es allí donde muestra la rutina de una dama del nivel social de la clase media alta de El Salvador.

Mamá ni siquiera iba al mercado. Era la Cata. Después del desayuno planear el menú con la cocinera, ver si están brillantes los pisos y los cobertores estirados, regar el patio, arrancar la maleza de las plantas. Un rato para leer o escribir cartas; para sentarse, simplemente, si hace mucho calor. A las once llegan los niños del colegio y el tiempo pasa rápido hasta que se vuelven a ir. Entonces viene la siesta a las tres, el refresco, a las cuatro sale papá a visitar a sus pacientes y mamá escucha música o lee. A las cinco volvemos del colegio y comienzan las visitas a llegar sin anunciarse. Un interminable chorro de parientes; llegan a masticar el mismo chisme, lo mastican, lo gustan, lo vuelven a masticar hasta que otro mejor aparece (p.16).

La señora de la casa era el alma del hogar. El objetivo de ella era el de organizar que todo estuviera en su lugar y asegurarse de no ser ella la causa del chisme que podría ser parte de las entretenciones sociales. Este era un patrón conductual de la época. En España, en el siglo XIX, aparece literatura especial para la mujer. Libros y periódicos para aprender a ser una dama. Una revista característica es El Ángel del Hogar de Pilar Sinués (Guardia, 2007, p. 20). En la siguiente frase se ve una muestra de ese pensamiento: “(...) viviré para educar a mi Teodora; pero como se debe educar a la mujer; esto es, para que sea el ángel tutelar del hombre a quien se una y no el ángel destructor" (Sinués. 2009, p. 355).

Carmen se detiene a observar la casa y piensa que todo lo que está en la casa, incluyendo la gente, va a padecer por la falta de su madre, y dice: "Tengo que decirle a Cata que cuide estas plantas. Se van a secar sin ella. Papá, las plantas, cuántas otras cosas. ¿Qué se sacaría si yo desapareciese repentinamente?" (Alegría, 1987, p.16). Carmen, además de iniciarse fuertes cuestionamientos acerca de su vida, se empieza a preocupar por todo lo que ha rodeado a su madre y cómo todo esto no va a subsistir por la falta de su madre Isabel; lo piensa como un ecosistema natural, donde la falta de uno de los elementos hace la desaparición de los otros. Sin embargo, Frank introduce una idea opuesta a la anterior: es él quien le hace ver a Isabel, en su afán por convencerla a que huya con él, que ella no es más que un objeto en esa casa:

-No amas a Alfonso — dijo-, te ha engañado, te trata como a esposa, propiedad privada, bien inmueble. Sonrió con exageración. - Eres un bien móvil, Isabel (...). Para él tú eres "esposa", "madre”, "ama de casa" en la misma medida que una "maceta" es una maceta (p. 149).

Es esta descripción de Frank la que puntualiza la visualización de la mujer en la década de los treinta, cuando aquella todavía no había sido considerada como 
una ciudadana. Sobre este hecho se tiene una sola cita en el libro, donde Isabel pronuncia claramente que las mujeres no votan: "Las mujeres no votamos en El Salvador — dijo - Cuando los hombres empiezan a discutir política, nosotras cerramos los oídos y pensamos en cosas más importantes. A propósito - se levantó-, ya la cena está lista" (p. 42). Pareciera ser que Isabel está conforme con esa política, sin embargo, el hecho de agregar "pensamos en cosas más importantes" muestra un claro tono de acusación irónica.

El año en que esta conversación está siendo llevada a cabo es el de 1932. En efecto, en la realidad histórica de ese mismo año, la mujer salvadoreña aún no tenía derecho a votar. Así se mira en el siguiente enunciado:

Dos años después de la muerte de “Doña Prudencia”, el 11 de julio de 1936, con los esfuerzos de la "Confraternidad de Señoras", las mujeres tendrían en sus manos los primeros frutos políticos. A partir de 1938, el sexo femenino comienza a figurar en la política nacional cuando el gobierno del Coronel Osorio, acepta un acuerdo de la Asamblea Nacional, donde se reconocía, mediante decreto, el derecho de las salvadoreñas para emitir su voto como ciudadanas (Murcia, Clic.org).

Como se puede ver en este discurso, la mujer no es más que un objeto de pertenencia. Es, así mismo, la esposa y la madre, pero sobre todo la embellecedora del hogar, un hogar que sin su presencia se marchita como una planta.

De este modo, la denuncia social de Alegría se nos muestra a través de diversos personajes, entre ellos Eduardo, Virgil y por supuesto Frank. Es interesante ver cómo la realidad social de más peso se introduce a través de las voces masculinas de ellos tres. En este sentido, hay un juicio de valor. La autora considera que la sociedad prestará más atención si la voz narradora de los sucesos políticos es masculina. En el tiempo narrativo de la obra todavía las mujeres salvadoreñas estaban alejadas de la ciudadanía, del espacio público por excelencia, que es la vida política.

Claribel Alegría quiere transmitir su mensaje y se vale de los recursos que sean necesarios para que su palabra sea escuchada. Utiliza desde el título de la novela hasta los personajes que intervienen en ella para recobrar la memoria de una parte de la historia de los salvadoreños. Como ejemplo de esto se tiene el título de la novela, Cenizas de Izalco, refiriéndose al volcán de Izalco, el cual ha sido como un emblema patriótico para todos los salvadoreños. Sus erupciones, cuando estaba en actividad continua, fueron majestuosas, al punto de ser llamado "el faro del Pacífico". Unir este símbolo patrio a lo largo de toda la narración provoca un sentimiento de identificación nacional que permite ver más de cerca el dolor en la pérdida y en la injusticia de la propia gente salvadoreña. 
De este modo, el título de la novela viene a ser de gran importancia. Primero, evoca un hecho real, ya que el volcán de Izalco se mantuvo activo durante muchos años, pero precisamente el año de 1932 coincidió la erupción con la matanza de los campesinos de la zona occidental del país (Alvarenga, 1996, p.9), una de las matanzas más sangrientas y duras de la historia de El Salvador. En el periódico Vértice, bajo el encabezado de "1932: setenta años después", se relatan los hechos sucedidos:

Antes de la medianoche del día 22, con la erupción del volcán de Izalco como marco cinematográfico, varios miles de campesinos se lanzaron a la invasión de poblaciones como Villa Colón, Juayúa, Salcoatitán, Sonzacate, Izalco, Teotepeque, Tepecoyo, Los Amates, Finca Florida, Ahuachapán, Tacuba y otras poblaciones más, azuzados por los dirigentes comunistas y armados con machetes y algunos cientos de fusiles (1932: Vértice).

Fue precisamente por esa insurrección de los campesinos por lo que luego fueron castigados tan injustamente. Su castigo, como narra Claribel Alegría, fue ser asesinados a sangre fría, como animales "rabiosos" a los que había que eliminar. Se les pidió que entregaran sus machetes y que se concentraran en la plaza de Izalco donde se les iba a dar un discurso. Media vez estuvieron todos reunidos en la plaza, todos ellos fueron ametrallados. En el año de 1932 gobernaba en El Salvador el general Maximiliano Hernández Martínez.

En uno de los pasajes de la novela, Frank relata, en la última entrada en su diario, la huida de una emboscada perpetrada por los campesinos al autobús donde él iba. Frank describe la euforia de rebelión que llevaban los indígenas y de cómo él logra escapar. Todo el viaje de Frank en el autobús y su huida, así como su supervivencia en el campo y la vivencia de la matanza, es un rito de pasaje en donde las cenizas y la erupción del volcán pasan a ser más que un simple trasfondo del paisaje. Primeramente menciono el hecho de ser un rito de pasaje porque se produce una revelación en Frank. Todo ese viaje que le produce una internalización de la crudeza de los hechos históricos de ese momento. Como señala Cirlot: “(...) Viaje no es una huida ni un sometimiento, es evolución (...). Las pruebas —y las etapas del viaje_- son ritos de purificación. (...)” (p. 472). En este sentido, la novela de Alegría combina ese viaje de Frank con las cenizas del volcán y su erupción. En todo el diario de Frank aparecen menciones de movimientos de la tierra a causa del volcán, humos y cenizas saliendo de él. Es como si el volcán fuera esa presencia continua en movimiento que, a causa de una fuerza natural, no puede ser contenida y tiene que salir porque la presión ejercida ya no puede resistir.

Alegría presenta la erupción del volcán en relación con el hecho de la sublevación de los campesinos. Era algo que se venía preparando y, al ponerlo en conjunto con la erupción del volcán, muestra la temática discursiva de la autora. La 
naturaleza, para Claribel Alegría, no se puede controlar. El campesino, como ser indígena, representado por la cultura occidental como ser próximo a la naturaleza, sale de las tierras a la ciudad para ajusticiar a los que los oprimen. Lo que sucedió a causa de ese levantamiento fue el orden puesto con extrema violencia por los militares, hecho conocido como "La masacre del 32".

A través de toda la obra, Alegría denuncia la calidad inhumana y la extrema pobreza en la que viven los campesinos y el hecho de que todo sigue igual. Son treinta años el período temporal de la novela, y al referirse en el presente narrativo alude a que "todo está igual que antes (...) no pasa nada en Santa Ana. Los días, los meses, los años no significan nada” (Alegría, 1987, p.72).

La denuncia de Alegría es clara y rotunda en muchas propuestas. Así afirma lo siguiente:

Para el tiempo de corte se van a las fincas con sus padres; les pagan por tarea, no les dan su ración de comida, porque dicen los patrones que no rinden lo suficiente (...) este país no podrá prosperar hasta que sus niños no se alimenten mejor, hasta que en vez de cantinas se construyan escuelas (p. 31).

Luego presenta una conversación con las dos señoras, Meches y Celia, que han llegado a visitar a Carmen y a su padre, algunos días después del entierro de Isabel, la madre de Carmen. En ese dialogo presenta una posición de la clase alta salvadoreña ante el trato que las autoridades y los terratenientes le dan a los pobres:

Antes de que te vayas — dice Meches-tienes que venir a ver la casa que le regalé a Lito y Tere (...) por supuesto que me ha costado una fortuna; hemos hecho traer rosas de Inglaterra y plantas raras de la India que Lilo quería. Hay una piscina (...). Es el único lugar que tiene agua en toda la región (...) toda la piedra de la pared de enfrente, la hicimos venir de Guatemala; los azulejos de los baños (...) todito se pidió de los Estados Unidos. (...) Lo único malo, doctor - continúa Meches inexorable-, es el traspatio, donde tenemos la bomba, se mantiene lleno de gente que llega a comprar agua. Son tan sucios, (...) A veces me dan ganas de quitar la bomba, pero es un buen negocio (...) es el único lugar donde hay agua por ahí (p. 71).

Con este diálogo la escritora presenta el juicio de valor que está en juego: el lujo frente a la necesidad. La frase que se marca en negritas es para resaltar el hecho de suprimir el único lugar de abastecimiento de una necesidad extremadamente básica para la subsistencia humana, como el agua, y de la cual están sacando aun provecho las clases dirigentes, ya que no la regalan sino que la venden. 
En otro segmento del libro, Frank acompaña a Virgil a las afueras de Santa Ana para examinar a unos cerdos. En el discurso de Virgil se tiene una denuncia más clara y directa de la realidad que el observa:

- ¿Qué piensas - exclamó Virgil- de esas barriguitas hinchadas, de la suciedad en que viven? Hasta diez personas viven en un solo cuartucho - continuó-, dos y tres en cada catre, y los demás en el suelo. Un parasicólogo tendría que estar ocupado por lo menos tres meses con esos seis niños que estaban junto a la puerta (...) más de la mitad fallecen antes de cumplir un año. (...) Nunca beben leche ni comen carne (p. 85).

Luego el diálogo entre Eduardo (hermano de Isabel y a favor de los cambios que proponía Farabundo Martí, el cual aparece en la obra con su propio nombre y apellido) y Frank expresa claramente cómo Alegría utiliza la obra como una herramienta de denuncia social. En este pasaje, Eduardo le dice a Frank:

Traté por un momento de ver la realidad. El ganado que acabamos de dejar atrás, camino al matadero, no es de las gentes que lo guían, ni siquiera son de ellos las carretas o los bueyes. Don Juan Domínguez es el dueño (...) Todo lo que ve, con excepción de la grava, las líneas de teléfono y este auto está exactamente igual desde hace doscientos años (...) ¿Cómo le gustaría a usted ser tratado como un burro toda su vida y ver a sus hijos crecer en la misma miseria, sin poder ir a la escuela? (p. 96).

En la cita anterior también se puede notar la repetición de la preocupación de Alegría por el hecho de que los niños pobres no van a las escuelas. En ese fragmento agrega el factor de que no hay ninguna movilización social. En otra conversación familiar, y en el tiempo presente narrativo, alrededor de 1960, Carmen pregunta: — ¿No hay escuela en la finca?/ — Lo que hay es un cuartucho con piso de tierra. Dice que es deber del Estado levantar las escuelas. / _iQué horror! — digo_- nada ha cambiado aquí en los últimos treinta años (p. 127).

Continúa la gran preocupación de la autora por hacer ver la falta de educación en el sector trabajador del país.

Frank, al haberse escapado de los campesinos insurgentes, se encuentra perdido en la selva y cerca del volcán de Izalco: "Las cenizas seguían cayendo sobre mi rostro mientras la luz demoníaca iluminaba los árboles y el camino cada vez con mayor intensidad" (Alegría, 1986, p.154).

De las cenizas, dice Cirlot que simbolizan el instinto de la muerte y que surgen como amenaza. Así, Alegría (1987) afirma: 
Una ola de lava se abrió paso a través de una grieta en el cráter (...) La corriente de lava se convirtió de pronto en el poderoso brazo de Tlaloc, que salía del cono (...) Estaba despierto. Tlaloc, se preparaba a levantarse, a salir de su cráter, a caminar su tierra una vez más, sembrando terror y muerte y destrucción (Alegría 1986, p.156).

Frank logra llegar al pueblo de Izalco donde se entera de que hacía unos días los campesinos se habían levantado, con machetes, en un intento de rebelión contra sus opresores. Frank trata por todos los medios de tomar un transporte que lo lleve a Santa Ana, lo que le es imposible, por lo que el personaje de Frank se convierte en un testigo visual que permite al lector entrar a través de sus ojos a presenciar una escena aterrorizadora: -Desarmamos a los campesinos de la región - dijo - . Hay órdenes de fusilar a cualquiera que se encuentre esta tarde con machete o sin salvoconducto. (...) —Nadie sale — nos informó un sargento gordo (...) hay órdenes estrictas de que nadie salga (Alegría, 1986, p. 167).

Todos los campesinos desarmados, estaban reunidos en la plaza. Frank y Virgil, que había llegado a recogerlo, lograron entrar en una cantina mientras esperaban a que el general llegara a dar su discurso a los campesinos reunidos en la plaza. "Se estiman que entre 15.000 y 30.000 personas" (Alvarenga, 1996, p. 17).

La culminación de la novela es la parte más trágica, donde la escritora "genéricamente" pretende desequilibrar emocionalmente al lector. Así, nos entrega una escena dura, cruel y altamente conmovedora, donde sin quererlo uno se hace presente junto a Frank en esas líneas que él mismo escribió en su diario:

En eso se oyó la primera raca taca taca de ametralladoras. - iPor Dios!, Frank, es una emboscada. Disparan desde los camiones. (...) Las ametralladoras estaban montadas en los camiones, con oficiales manejándolas. Mientras mirábamos la masa de campesinos en el espacio abierto de la plaza, salía de su estupor (...) Yo estaba paralizado, todavía sin poder dar crédito a lo que mis ojos contemplaban. Los rimeros de cadáveres formaban una masa enmarañada que protegía los camiones. (...) Todo esto pasó en menos de un minuto (...). Aun con media docena de ametralladoras lleva tiempo matar cinco o seis mil personas (Alegría, 1987 pp. 169-171).

En este último pasaje está claro que la escritora Claribel Alegría quiso perpetuar la memoria de un pueblo a través de la historia sangrienta relatada en esta novela. Alegría combina las necesidades existentes de la pobreza salvadoreña, donde Carmen está constantemente indignada por la falta de desarrollo y escuelas en su país y el caso de la opresión que llevó a los campesinos (en su mayoría indígenas) a sublevarse. 


\section{Conclusión}

Hasta aquí, se demuestra cómo Claribel Alegría se ha sabido comprometer con la historia de su país y que se vale de sus obras literarias para hacer así una profunda denuncia social, tanto sobre la opresión de la mujer que se ciñe a las normas sociales como al sufrimiento de un pueblo que está bajo un poder opresivo. La escritora reclama a las emociones del lector para presentar las injusticias o situaciones políticas existentes.

Claribel Alegría presenta una analogía sobre la opresión misma que la mujer siente y la que ha llevado a los indígenas a sublevarse. Plantea el entendimiento de Frank hacia el por qué Isabel no se podía ir con él, al mismo tiempo que Frank observa a través de una ventana de una cantina, en la plaza de Izalco, la masacre del 32.

Cuando Frank observa a través de la ventana, es como si estuviera viendo a través de Isabel; y se da cuenta que intentar un cambio es derramar sangre y sufrimiento en sus descendientes. Por eso decide irse, comprende que Isabel no se puede ir con él porque él no es capaz de pedirle que se subleve contra las normas sociales, ya que esto traería mucho sufrimiento no solo a Isabel, sino también a los hijos de ella. Lo interesante es que Frank hace esta toma de conciencia cuando mira a través de la ventana.

La escritora hace uso de su personaje para introducir a los lectores en ese momento. El lector forma parte de los testigos del castigo de un pueblo. De la ventana, dice Cirlot (1997): "Por su forma cuadrangular, su sentido se hace terrestre y racional. Es también un símbolo de la conciencia" (p. 470). Frank razona lo irrazonable y entiende que ya no puede seguir insistiéndole a Isabel que deje a Alfonso. Él toma conciencia del papel de ella y de que él es el que está de más y que solo fue un forastero, tanto en la ciudad como en el cuerpo de ella. Aun en esto último se ve una analogía: como madre, o Magna Mater (patria, ciudad, naturaleza), bajo el significado de Cirlot. Isabel, como la ciudad, es una mujer ya habitada. El amor que vivieron la mañana que se entregó a él quedó reducido a polvo, tomándolo bajo la connotación sexual, ${ }^{3}$ polvo que desaparecerá y se confundirá con la tierra; igual que los cadáveres quedarán convertidos en polvo. Isabel es enterrada con sus muertos y le echan la tierra negra del volcán, misma que lleva las cenizas de los muertos que vivieron oprimidos. No solo la están enterrando con sus muertos, literalmente hablando, pues le ponen los huesos de sus familiares muertos, como es costumbre, sino con sus pasiones muertas que fueron enterradas en el pasado, en la opresión de su instinto por sobrevivir bajo los conceptos normativos de una sociedad.

En definitiva, en esta investigación se puede observar cómo la escritora Claribel Alegría es una mujer que ha traspasado, con sus ideas, las fronteras literarias.

3 Coloquial y vulgar, según la Real Academia Española 
Su obra Cenizas de Izalco, al igual que su protagonista Frank, se llevará afuera de las fronteras nacionales un testimonio que denuncia la realidad salvadoreña.

Claribel Alegría ha puesto y entregado sus denuncias a través de su literatura; ha escrito textos comprometidos con la dignificación del ser humano. Esta escritora nos da fechas, lugares y eventos. Su obra literaria está impregnada de una voz comprometida que expone los aspectos normativos de la mujer y denuncia la situación política y social de El Salvador.

\section{Fuentes primarias}

Alegría, Claribel, y Flakoll. Darwin J. Cenizas de Izalco. 1. ${ }^{a}$ ed. San Salvador: UCA, 1987.

\section{Referentes bibliográficos}

Alvarenga, Patricia. Cultura y ética de la violencia. El Salvador 1880-1932. $2^{\mathrm{a}}$ ed. Vol. 19. San José: Educa, 1996.

Araya, Seidy. Seis narradoras de Centroamérica. San José: Editorial de la Universidad Nacional (Euna), 2003.

Cirlot, Juan Eduardo. Diccionario de símbolos. Madrid: Ediciones Siruela, 1997.

Duarte de Romero, Refugio. Mujeres en la literatura salvadoreña. Red de mujeres escritoras salvadoreñas. $1^{a}$ ed. San Salvador: Imprenta Public, 1997.

Gil Casado, Pablo. La novela social española, 1920-1971. Barcelona: Editorial Seix Barral, 1973.

Guardia Herrero, Carmen. Los discursos de la diferencia. Género y ciudadanía. La ciudadanía en España, Manuel Pérez Ledesma editor, Madrid, Centro de Estudios Constitucionales, 2007, pp. 593-625.

Martínez Peñate, Óscar. El Salvador. Historia General. $2^{\mathrm{a}}$ ed. San Salvador, 2002.

1932: SETENTA AÑOS DESPUÉS. Vértice. El Diario de Hoy, 20 Jan. 2002. Web. 12 July 2009.

http://www.elsalvador.com/vertice/2002/01/20/indigenas.html.

Origen del Vulcanismo en El Salvador". SNET-Servicio Nacional de Estudios Territoriales. Servicio Nacional de Estudios Territoriales. Web. 21 July 2009.

http://www.snet.gob.sv/Geologia/Vulcanologia/paginas/origen.htm.

Parkman, Patricia. Insurrección no violenta en El Salvador. ${ }^{\text {a }}$ ed. Vol. 13. San Salvador: Dirección de Publicaciones e Impresos, 2003. Biblioteca de Historia Salvadoreña.

Sinués de Marco, Pilar. "Sueño". Ángel del hogar. 08 Dec. 1865: 354-55. Hemeroteca Digital-Biblioteca Nacional. Web. 20 July 2009. http://hemerotecadigital.bne.es/cgi-bin/Pandora. exe. 2009. 
http://www.tec.cr/sitios/Docencia/ciencias_lenguaje/revista_comunicacion/Vol.12No22002/ pdf's/jvargas.pdf.

Vargas, José Á. "La incorporación de la voz femenina”. Web. 02 July Zavala, Iris M. En Breve historia feminista de la literatura española. 1. a ed. Barcelona: Anthropos, 1998. 


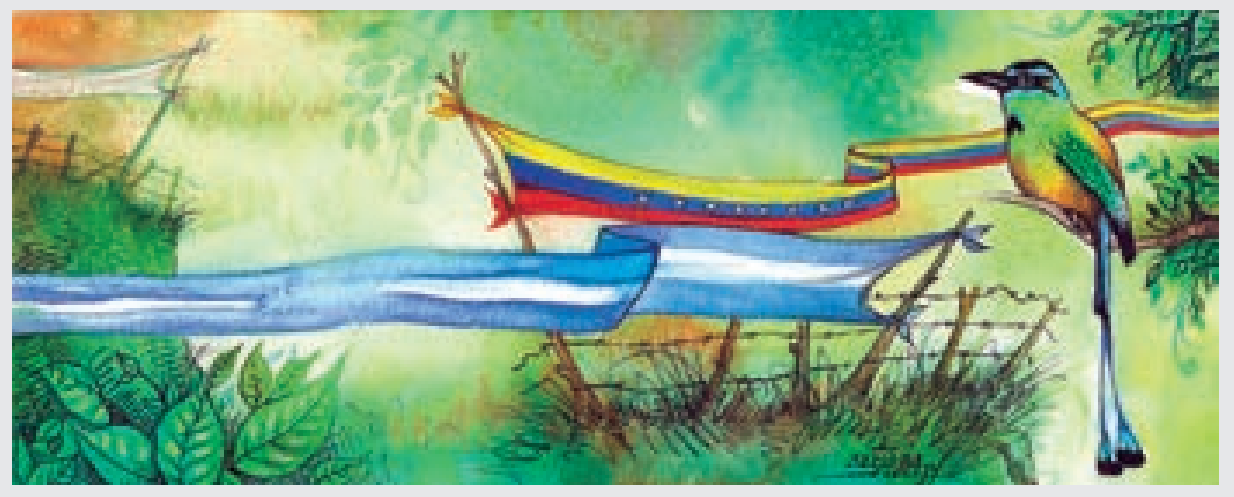

